\title{
The Indeterminacy of the Distinction between Objects and Ways of Being
}

\author{
Julio De Rizzo ${ }^{1,2,3}$
}

Received: 15 January 2020 / Accepted: 9 October 2020 / Published online: 23 November 2020 (c) The Author(s) 2020

\begin{abstract}
Few if any distinctions are more easily recognisable and assented to than that between objects, that is, things which are some ways, and that which they are, that is, ways for objects to be ('ways of being' for short). In this paper I present an argument designed to show that this distinction is indeterminate in the sense that the truth-conditions of predicational sentences leave open what should count as an object and a way of being. The bulk of the argument is inspired by the celebrated permutation argument advanced by Quine, Wallace, Putnam and others.
\end{abstract}

The story has it that the people of Yesmar, a small island in South America, spoke a language curiously distinct from ours. For Yesmarish didn't have a device corresponding to our copula: to state a simple monadic predication, a Yesmarian would simply list two words. Importantly, the order would not affect meaning. When stating time tense, plurals, or simple quantifications, one would simply add a device to either of the two words, again without a change of meaning between both choices. Besides, Yesmarians didn't have a procedure for deriving singular terms from general terms, as we do by means, for example, of the suffixes 'ness' or 'ity', which allows us to form 'redness' and 'simplicity' from 'red' and 'simple', respectively. As a matter of fact, linguists of the time claimed to have conclusive evidence that no distinction between a singular term and a general term would make sense to a Yesmarian in the first place. Thus, faithful translators of Yesmarish into English would always face a choice between various formulations. Confronted with a white rabbit, a Yesmarian would utter a construction strictly comparable to 'rabbit white', 'white rabbit', 'whiteness rabbithood', 'rabbithood whiteness', 'white rabbithood', 'rabbit whiteness', and so on, all meaning simply that a certain rabbit is white.

Julio De Rizzo

julioderizzo@gmail.com

1 Department of Philosophy, University of São Paulo, São Paulo, Brazil

2 Department of Philosophy, University of Hamburg, Hamburg, Germany

3 Fachbereich Philosophie, Universität Hamburg, Überseering 35, Hamburg 22297, Germany 
Of course, the story of Yesmar is probably nothing more than a curious fiction. But the possibility of such a language, if it can be established, would be of obvious philosophical interest. For Yesmarians who came to know English and learn about the singular and general term distinction would seemingly not hesitate to insist that it is not a substantive matter which of 'This rabbit is white' or 'This whiteness rabbitises' fares better when it comes to a description of what goes on in reality. ${ }^{1}$ To put this in other terms, to ask of the obtaining fact rendering both sentences true whether it has the rabbit or the particular instance of white as objects, and the being white of the former or the rabbitizing of the latter as ways for the corresponding objects to be, would be disregarded as utterly out of place by the Yesmarian philosopher.

Now even if it turns out that Yesmarish does not correspond to any actually observed language, it remains an open question whether English, and other existent idiolects, would allow for the same moral to be drawn. In what follows, I will put forward an argument for the thesis that we have no sufficient grounds for deciding between 'Socrates is wise' and '(This) wisdom Socratises' as a better way of representing reality 'in itself' (I will add some qualifications on this below). The essential part of the argument follows closely the celebrated permutation arguments presented by Quine, Wallace and most famously by Putnam.

Here is a roadmap of what follows. In the first section, I will lay bare some preliminary distinctions and clarify the thesis aimed at. In the second section, I will present the argument and proceed to motivate its premises. The defence of one of these follows closely the main tenets of the permutation argument mentioned above, which is stated in its original form (Sect. 2.1) and then presented in modified form suitable for our purposes (Sect. 2.2). In the third section, I will then briefly draw some consequences the conclusion might have to other debates. The final section concludes.

\section{On What there is and What is There for Things to be}

Few if any distinctions are more easily recognisable and assented to than that between objects, that is, things which are some ways, and ways for things to be, that is, that which things are, which I will label 'ways of being' for short. Thus we say for example of Socrates that he is wise, that one of the ways Quine is is American, or of the numbers 3 and 2 that they stand in the larger than relation. In short: in declarative subject-predicate sentences some bits of reality, the ways of being, are said to 'characterise' other bits, the objects.

At the outset, it merits comment that, as understood here, talk of ways of being does not match with talk of properties, which is perhaps more often countenanced

\footnotetext{
1 Singular terms such as 'this whiteness', 'this wisdom' and so on are meant to express particularised properties, so-called 'tropes' in the literature. See Mulligan et al. (1984). Though a transformation of e.g. 'Socrates is wise' into 'This wisdom Socratises' suggests itself, given that the main point of the text does not depend on the acceptance of tropes, I will insert 'this' between brackets when stating examples ('(This) wisdom Socratises') in order to highlight this as an open choice.
} 
in philosophical discussion. For properties are more commonly and naturally taken to be referred to by singular terms, or property designators, such as 'whiteness', 'the property of being a rabbit', 'wisdom', and so on (Schnieder 2006a), whereas ways of being are expressed by general terms. Thus, strictly speaking, the property of wisdom, for instance, is not a way Socrates is. This might be made explicit by setting the property designator after the 'namely'-rider, as in 'Socrates is something, namely the property of wisdom', which depending on the reading of 'is' - as the predicative copula or as expressing identity-is either nonsensical or expresses an utter falsehood (Sellars 1960; Levinson 1978). Surely, properties and ways of being closely relate to one another, as already a glance at the expressions semantically related to them suggests (Schnieder 2006a: 320ff.). For our purposes, and in order to prevent misunderstanding, it is important to keep them apart. ${ }^{2}$

For the sake of simplicity, I will concentrate on non-relational, that is monadic, ways of being in what follows. Moreover, as already gestured at, when speaking of ways of being, I will focus on general terms such as 'wise' or 'American' rather than whole predicative expressions such as 'is wise' and 'is American'. For one, most natural languages seem to underwrite quantification only into general term and singular term positions, not into the position of whole predicates (cf. Sellars 1960; Rayo and Yablo 2001). We thus say that there is something Quine is, namely American, or that wise is among everything Socrates is. Since we are ultimately inquiring about whether reality answers to a distinction, it seems more natural to frame the issue as revolving around items we can speak and quantify over. Besides, this leaves intricate questions around the semantics of the copula 'is' untouched: whether it signifies a tie, or is merely an indicator of an assertion without any semantic correlate of its own, or maybe further arguably less natural options, will have no bearing on our discussion. This being said, the mentioned focus notwithstanding, I will also treat non-copulative verbs and verbal expressions as semantically related to ways of being. This corresponds to standard regimentation strategies of e.g. 'Quine reads' in terms of a copula (e.g. 'Quine is a reader'), and allows for more generality in the overall account.

The exposition of the distinction between objects and ways of being is meant to be neutral in important respects. Firstly, for our purposes I will leave aside the subservient distinction between semantic relations general terms and singular terms bear to their semantic values, for instance expression and reference, respectively (cf. Künne 2006; MacBride 2006). For the most part, I shall continue speaking neutrally

\footnotetext{
${ }^{2}$ Ways of being and properties are not always explicitly distinguished in the literature, and some philosophers even seem at times to speak against the relevance of the distinction (see e.g. Strawson 1974: 33). For explicit acknowledgments (not necessarily in the same terms), see Sellars (1960), Levinson (1978), Prior (1971: chapter 3), Rayo and Yablo (2001), Krämer (2014). Besides, strictly speaking, since 'ways of being' is a count-noun, my use of this term invites the objection that, in order to say that something is a way of being, one would have to be able to refer to ways by means of singular terms, and we are not. Similar difficulties underlie the use of 'bits of reality', 'items', or 'semantic values' to cover both objects and ways of being. This is, of course, closely related to the traditional and long-debated 'concept horse' problem, upon which I shall not dwell here. Since we need terms for framing the issue, this might be a ladder one needs to climb anyway. Thanks to an anonymous reviewer for suggesting me to make this explicit.
} 
of a term expressing or semantically relating to its value. Secondly, the distinction between objects and ways of being thus framed ought to be silent regarding the delicate questions a somewhat neighbour distinction, namely that between particulars and universals, gives rise to. Put in other terms, for present concerns it is immaterial whether ways of being are aptly regarded as shared or wholly present in the objects they 'attach' to, or whether they are to be conceived of as abstract, non-spatio-temporal, and so on. ${ }^{3}$

With the foregoing clarifications in play, let us distinguish between two theses. On the one hand, there is the claim that there is a distinction between objects and ways of being in the sense presented, but it is not a determinate issue what should count as an object and what should count as a way for objects to be. To put it in more dramatic terms, though reality exhibits a predicational structure, beyond this it is not an objective, metaphysically robust matter what should fall under these categories. On the other hand, there is the more radical claim that the distinction between objects and ways of being is not warranted at all, that is, it is an indeterminate matter whether reality underwrites a predicational structure in the first place.

In view of the fact that it requires a strongly revisionary attitude towards a distinction most of us put regularly to use in many different languages and find perfectly intelligible, the more radical thesis requires a much more ingenious argument than the one I shall provide shortly. Indeed, prominent considerations aiming at establishing the distinction seemingly speak against the radical thesis, while arguably leaving the first thesis untouched. To illustrate this, consider Strawson's suggestion that ways - what corresponds to what he labels 'general characters' - are to be distinguished from objects-what corresponds to what he labels 'particulars' - in that the former come in families of incompatible items, such as blue, red and every other colour, while objects do not exhibit this characteristic (Strawson 1971: 101 ff.). If this is right, it settles that objects and ways of being are to be distinguished, which renders the more radical thesis false, but in itself it is nonetheless silent as to whether it is an objective matter which of 'Socrates is wise' or 'This wisdom Socratises' most aptly represents reality: for all the proposed distinction states, it might turn out that Socratises stands in an incompatibility family with other ways of being-Platonises, Aristotelises, and so on-, while 'this wisdom' picks out the particular predicated of. ${ }^{4}$

In the following, the weaker thesis announced will be at stake. Let us say that an exclusive distinction between P's and Q's is indeterminate in case we cannot settle on satisfactory grounds, concerning at least some cases, whether they are to be classified as P's or Q's. In a nutshell, thus, the thesis to be considered states that the

\footnotetext{
${ }^{3}$ For doubts concerning the distinction between universals and particulars, see for instance (Ramsey 1925) and more recently (MacBride 2005). Throughout the paper, I will assume sentences asserting relations also fall under the subject-predicate structure. Since it is controversial whether there are relational universals, this might be a further point in which both distinctions might not coincide.

4 Though this reply might depend on formulating the alternative to 'Socrates is wise' in terms of tropes, I take it that this does not blunt its force, since the criterion we are examining should be applicable in this case as well.
} 
distinction between objects and ways of being is indeterminate in this sense (more in due course).

It is instructive to examine briefly a thesis in the vicinity, suggested by the following famous remarks by Ramsey:

Now it seems to me as clear as anything can be in philosophy that the two sentences 'Socrates is wise', 'Wisdom is a characteristic of Socrates' assert the same fact and express the same proposition. They are not, of course, the same sentence, but they have the same meaning, just as two sentences in two different languages can have the same meaning. Which sentence we use is a matter either of literary style, or of the point of view from which we approach the fact. (Ramsey 1925: 12)

Taking some liberty of interpretation-since, for one, Ramsey is explicitly concerned with the distinction between particulars and universals-these remarks are arguably useful to cast light upon the thesis we are beginning to consider. To be sure, for our concerns, the text is unnecessarily strong: Ramsey suggests not only that 'Socrates is wise' and 'Wisdom is a characteristic of Socrates' assert the same fact, but that they have the same meaning. ${ }^{5}$ Again, to fix terminology, let us speak of two sentences which assert the same fact as factually equivalent, in the sense that they only differ, if at all, as to the representational resources employed, not to 'the facts' they somehow answer to (see Correia 2016, from whom I borrow the term). ${ }^{6}$ To see that both points should be kept apart, notice that requiring sameness of meaning, or synonymy, of factually equivalent sentences would be overly strong: ' Socrates is wise', for instance, is factually equivalent to 'Socrates is wise', if anything is, but since a proper understanding of the first presupposes the concept of negation, the two sentences are not synonymous; 'There is water in this glass' and 'There are $\mathrm{H}_{2} \mathrm{O}$ molecules in this glass', 'Hesperus = Phosphorus' and 'Hesperus $=$ Hesperus' also illustrate this.

The point which seems to relate more closely to what follows pertains only to the factual equivalence between sentences such as 'Socrates is wise' and '(This) wisdom Socratises' (which I take to be sufficiently close to Ramsey's own example), that is, speaking again in dramatic terms, that the reality 'answering to' both sentences is indifferent to whether we frame (this) wisdom and Socratises, or Socrates and wise as object and a way for it to be, respectively. I hasten to stress, however, that factual equivalence goes beyond what the argument to be stated aims to show, that is, it strictly speaking falls short of demonstrating that sentences thus related are factually equivalent. Anticipating a bit, the indeterminacy to be argued for below takes us only as far as to say that, concerning one and the same sentence, such as 'Socrates is wise', there are equally admissible interpretations which assign to either of the terms therein an object, while assigning a way of being to the other, therefore it does not touch upon the issue of factual equivalence (not in any trivial sense, at any rate).

\footnotetext{
5 For discussion and criticism of this synonymy thesis, see (Schnieder 2006a).

6 I do not intend here to rely on a specific view of facts, nor to suggest that we need commitment to facts. This terminology serves here purposes of exposition only.
} 
Nonetheless, the claim of factual equivalence certainly contributes for clarity of the point under discussion, since, if the main argument below succeeds, the motivations-at least those based largely on the semantics of sentences-which drive us to distinguish factually between sentences related as above seem to lose much of their bite. Thus, even if the indeterminacy does not entail the factual equivalence claim suggested by Ramsey, it certainly points in its direction. Bearing the mentioned limitation of the argument in mind, since it makes for a less cumbersome formulation, I will henceforth rely on the previous example as illustrative of the point at stake.

\section{The Main Argument Stated}

We now proceed to an explicit statement of the main argument:

P1. If the distinction between objects and ways of being is determinate, then the truth-conditions of sentences of subject-predicate form are sensitive to it;

$\mathrm{P} 2$. The truth-conditions of sentences of subject-predicate form are not sensitive to the latter distinction;

C. Therefore, the distinction is indeterminate.

By a truth-condition of a sentence $p$ I shall understand, as usual, what is expressed by a sentence of the form ' It is true that $p$ if and only if ... ' in a suitable metalanguage, couched in set-theoretical terms, for the object language to which $p$ belongs ( $\left\ulcorner\right.$, and $\left.{ }^{\prime}\right\urcorner$, are devices of selective quotation as suggested by Quine). I will assume an assignment of values for singular and general terms - an interpretation-settles the truth-values of every sentence in the language under consideration, via the truth theory, that is, the truth-conditions for atomic sentences and sentences governed by usual truth-functional connectives in the object language L. Two interpretations of $\mathrm{L}$ are equivalent iff they assign the same truth-values to every sentence of L. Finally, the truth-conditions of a sentence are not sensitive to the distinction between objects and ways of being - strictly speaking, relatively to a language L-if there are two equivalent interpretations of L disagreeing only in that they 'swap' some of the assignments to singular and general terms (more on this in due course).

I take it that under this way of framing the issue, the first premise has an air of plausibility to it. As a matter of fact, it might seem to rely on a modified form of the context principle famously held by Frege. According to one understanding of this principle, the meanings of sub-sentential expressions are somewhat settled by the meanings of the sentences in which they occur. It is plausible, as some indeed have, to interpret this determination as being testified by the truth-conditions of the sentences in question (cf. Wallace 1977; Dummett 2015). Now since objects and ways of being are categories taken standardly to be semantically related to singular and general terms, respectively, it would seem natural to suppose that a distinction between them pertains to the truth-conditions of whole sentences by the principle thus read. 
The second premise, in turn, will be supported by a form of argument close in spirit to the so-called permutation argument championed by Quine, Wallace, Putnam and others. As will be made clearer by the presentation of this sub-argument in the next sections, to an extent the aimed result is but a strengthening of Putnam's original: just as the permutation argument purportedly shows that the truth-condition of 'Socrates is wise' does not determine that 'Socrates' refers to Socrates, the extension to be presented shortly shows that the same truth-condition falls short of fixing Socrates or (this) wisdom as the object, and wise or Socratises as the corresponding way of being. (To be sure, this is not to claim that it is an indeterminate matter whether 'Socrates' and '(this) wisdom', and 'wise' and 'Socratises', function as singular and general terms, or subjects and predicates, respectively, in the corresponding sentences, but to claim that we ought not to read off from this syntactic classification an underlying 'real' object- way of being structure mirroring any one of these constructions. ${ }^{7}$ ) For clarity, I will follow this in the course of the exposition: the sub-argument in support of P2 will be presented as parallel to the original permutation argument.

Before proceeding, let me highlight a caveat. The argument concerns the determinacy of the distinction at hand insofar as it is meant to be settled by semantic features of sentences, in particular truth, which is a supposition expressed in the first premise. For all that, it might turn out that the distinction is on firm footing on other grounds, maybe features of our perception, intentional states, reasoning, theoretical economy, and so on. Since arguing for P1 properly would thus invite extended considerations of a whole different sort, which would go beyond the limits of one paper, I shall rely on P1 as an assumption. (Thus, strictly speaking, the main target of the present text is better stated in conditional form: If P1 holds, then the indeterminacy of the distinction at stake holds.) However, given that many would be tempted to hold the distinction on semantic grounds, that is, to be settled by how things stand in reality to which sentences semantically relate, and since the gist of the main argument lies in P2, I take it that the argument as proposed is still worthy of consideration.

\subsection{The Original Permutation Argument}

It is useful to provide a glance at the original permutation argument and outline the role it plays in the work of Putnam, who stands out as its most prominent contender. ${ }^{8}$ As presented by him, the argument is actually part of a series of arguments, usually labelled 'model-theoretic arguments', aiming to show that realism is committed to

\footnotetext{
7 For recent discussion on criteria for distinguishing singular terms from other types of expressions, see (Schwartzkopff 2016).

${ }^{8}$ As Putnam himself acknowledges, essentially the same argument is presented earlier by Quine in his (1960), and a related point is made even earlier by Frege in Sect. 10 of the first volume of his (1893/2013). Wallace (1977) states an analogous argument in the context of truth-conditional semantics usually associated with Davidson.
} 
untenable claims about the relation between language and the world it purportedly represents.

Realism is characterised by Putnam as a position according to which 'the world consists of some fixed totality of mind-independent objects', and 'there is exactly one true and complete description of "the way the world is".' Still according to the realist, 'truth involves some sort of correspondence relation between words or thought-signs and external things and sets of things.' (Putnam 1981: 49).

Though the exact interpretation of this larger picture is open to debate, since we are not dwelling on exegetical matters of Putnam's text, his attack on realism might be formulated by means of the following schematic argument:

$\mathrm{P} 1 *$. Realism about $\mathrm{S}$ is committed to the claim that there is a unique intended interpretation of theories about $\mathrm{S}$.

$\mathrm{P} 2 *$. If there is one interpretation of a theory, then there are many.

$\mathrm{C}^{*}$. Realism about $\mathrm{S}$ is false.

This construes the larger argument, in effect, as a reductio of realism. Though for expository purposes I formulated it in terms of relativised forms of realism concerning specific subject-matters-for which ' $S$ ' in the scheme stands-, it is plain that, given the generality of $\mathrm{P} 2 *$, the argument pretends to establish the falsity of realism tout court. The permutation argument, alongside less elementary results such as the upward and downward Löwenheim-Skolem and Gödel's incompleteness theorems, are used by Putnam to support P2* (Putnam 1980, 1981). ${ }^{9}$

Importantly, the permutation argument is meant to display a more specific flaw in the realist position, namely, that the truth-conditions of whole sentences are unable to settle which of many 'bits of the world' are expressed by their sub-sentential terms. Of course, it is debatable whether $\mathrm{P} 1 *$ reports a commitment of realism, or whether it is committed to the mentioned thesis that semantic relations of sub-sentential terms should be somehow fixed by the truth-conditions of the sentences in which they occur. Since, however, the argument to be stated shortly in favour of P2 does not turn on the success of Putnam's overall strategy, we might waive the issues it raises. In any case, I take it that Putnam's argument is still significant even if, as it turns out, it applies only to realist positions which underwrite these prima facie plausible claims.

Let us proceed to a presentation of Putnam's original permutation argument. Its precise statement makes use of basic model-theoretical machinery, but before introducing it, it is helpful to put the point in a less technical way.

Suppose we have a simple language consisting of the singular terms 'Garfield', 'Felix', 'Socrates', 'Aristotle'; general terms 'cat', 'Greek' and usual logical devices (including, for instance, the copula 'is' for forming usual atomic sentences). In their usual interpretation, 'Garfield' refers to Garfield; 'Felix' to Felix; 'Socrates'

\footnotetext{
${ }^{9}$ For detailed expositions and discussion of Putnam's model-theoretic arguments, see for example Hale and Wright (1997), Douven (1999), Dummett (2015), Taylor (2006: chapter 3 ) and Button (2013: chapter 2).
} 
to Socrates; 'Aristotle' to Aristotle; 'cat' receives $\{$ Garfield, Felix \}; and 'Greek' \{Socrates, Aristotle\} as values. As before, we call an assignment of values of this form an interpretation of the language. Per standard, assume a sentence of the form $\ulcorner a$ is $P\urcorner$ is true under an interpretation, for a singular term $a$ and a general term $P$, if and only if the value of $a$ is a member of the value of $P$ under the interpretation in question. Relative to the interpretation just sketched, the following atomic sentences come out true: 'Garfield is a cat'; 'Felix is a cat'; 'Socrates is Greek' and 'Aristotle is Greek' (besides identities). Now suppose that we shuffle the values of the expressions. Thus suppose we have it that 'Garfield' refers to Socrates; 'Felix' refers to Aristotle; while 'Socrates' refers to Garfield and 'Aristotle' refers to Felix. 'Cat' is now interpreted as the set $\{$ Socrates, Aristotle\} and 'Greek' as \{Garfield, Felix $\}$. As the reader might verify, exactly the same sentences come out true under this alternative interpretation. Thus the truth-conditions of sentences leave the underlying interpretation of the sub-sentential expressions of this language unsettled.

The result suggested by this toy example is general. That is, given a first-order language and an interpretation, we can always find interpretations which 'shuffle' the original one and under which the truth-conditions of sentences are preserved. To state this more precisely, define an interpretation $I$ of a first-order language $L$ as a function taking expressions of $L$ as inputs and delivering members or subsets of a previously fixed domain of objects $D$ as their values. If $E$ is a singular term, the value of $E$ under $I$, denoted by $I(E)$, is a member of $D$. If $E$ is a general term of arity $n$, the value of $E$ under $I$ is a set of sequences of $n$ objects belonging to $D$. As before, a sentence of the form ${ }^{\ulcorner} s_{1} \ldots s_{\mathrm{n}}$ is $\left.P\right\urcorner$, for $s_{1} \ldots s_{\mathrm{n}}$ singular terms and $P$ general term of arity $n$, is true under an interpretation $I$ if and only if $\left\langle I\left(s_{1}\right) \ldots I\left(s_{\mathrm{n}}\right)\right\rangle$ belongs to $I(\mathrm{P})$. (Truth for non-atomic sentences is defined as usual). A permutation of a domain D is a one-one function from $\mathrm{D}$ into $\mathrm{D}$. Let $f$ be a permutation of a domain $\mathrm{D}$ of an interpretation $I$. Relative to $I$ and $f$, a shuffled interpretation $I^{*}$ is an interpretation of $L$ such that for each singular term $E$ of $L, I^{*}(E)=\mathrm{f}(\mathrm{I}(E))$; and for each general term $E$ of $L$ of arity $n, \mathrm{I}^{*}(\mathrm{E})=$ the set of sequences $\left\langle\mathrm{f}\left(a_{1}\right), \ldots, \mathrm{f}\left(a_{\mathrm{n}}\right)\right\rangle$ such that $\left\langle a_{1}, \ldots, a_{\mathrm{n}}\right\rangle$ belongs to $\mathrm{I}(\mathrm{E})$. The claim then reads:

For every first-order sentence $p$ of L, every interpretation I and shuffled interpretation I* of I: $p$ is true under I if and only if $p$ is true under $I^{*}$. (The proof proceeds by induction on the complexity of $p$, and is presented in detail elsewhere. ${ }^{10}$ )

The result might be straightforwardly extended to modal languages, as Putnam himself states it. He takes it to show that "no view which only fixes the truth-values of whole sentences can fix reference, even if it specifies truth-values of sentences in every possible world.' (Putnam 1981: 33). That is, the semantic values of subsentential expressions are not determined by, hence not recoverable from, the assignment of truth-conditions for whole sentences.

Though I will not enter into a detailed discussion of the merits of this argument, some brief comments are in order. In the first place, by itself, the argument is not directed at those who take the semantic relations between sub-sentential expressions of the language and their values-mainly reference, in Putnam's case-as settled

\footnotetext{
10 See the 'weak permutation argument' in Hale and Wright (1997).
} 
offhand. That is, it aims to reduce to absurdity the claim that truth-conditions of whole sentences are underpinned by one particular semantic assignment to their sub-sentential parts, provided that one assumes that the assignment is somehow to be read off from the semantics of sentences. ${ }^{11}$

Furthermore, though the generality of the result-that is, that there are infinitely many alternative equivalent interpretations of a single language — surely adds weight to Putnam's contention, we should bear in mind that strictly speaking Putnam's claim would be established already if it were in every case possible to construe one distinct, 'shuffled' interpretation which preserved the truth-conditions of the original.

\subsection{The Argument for P2}

A somewhat straightforward extension of the permutation argument can be brought to bear on the determinacy of the distinction between objects and ways of being.

Before turning to this extension, one important remark is required. Since we aim to show that the truth-conditions of sentences cannot settle what is to count as an object and a way of being, we need at the outset to fix criteria for when the latter is the case in the set-theoretical framework in which the permutation argument is formulated. Since objects are modelled as members of the domain in question, and ways in our sense as sets construed from these members, I will adopt this as a criterion telling us when an expression relates semantically to these entities, relatively to an interpretation. (For simplicity, hitherto I will assume the elements of the domain of an interpretation are all urelements, so that this predicative character is aptly displayed by the assignment of a set to an expression. $)^{12}$ Again, I will first state the idea illustrated by a simple example, then proceed to a more general formulation.

Usually interpretations take at face value the distinction between singular and general terms of the language they are designed to interpret (as in Putnam's original argument above), that is to say, singular and general terms are treated differently by the interpretation function. The idea, now, is to drop this in the setting of interpretations. Let us deal with the same simple language as above for illustration. On the standard interpretation we have it that 'Garfield' has as value the object Garfield; 'Felix' has the object Felix; 'Socrates' has the object Socrates; 'Aristotle' the object Aristotle as semantic values; in turn 'cat' receives $\{$ Garfield, Felix $\}$; and 'Greek' \{Socrates, Aristotle\} as values. When considering a deviating interpretation, we

\footnotetext{
11 Hale and Wright (1997: 435). This parallels our reliance on P1 above. Putnam advances other arguments against these alternative views which are not ruled out by the permutation argument itself. See e.g. Putnam (1981).

12 In view of expected limitations of natural languages - at least those I am directly or indirectly acquainted with-, it is difficult to conceive of an interesting argument against the determinacy of the distinction which would proceed without an assumption along these lines, that is, without relying on surrogate objects to stand for ways of being. At any rate, requiring otherwise would either call for a metalanguage with no corresponding natural reading in English, or else would beg the question, since it would seemingly need to rely on some singular and general terms, as in the case of 'Socrates' and 'Socratises', semantically relating to 'the same thing'.
} 
now allow not only that the values be swapped among expressions of the same 'type', but also among singular and general terms. For simplicity, let us first suppose that the language does not have a predicate of identity. Thus consider an alternative interpretation I* under which both 'Felix' and 'Garfield' have the set \{Garfield, Felix \} as value; 'cat' has the object Garfield as value, and the rest is interpreted as the original interpretation above. In the axiom for truth of atomic predicational sentences, we now add:

A sentence of the form ${ }^{\ulcorner} a$ is $P^{\urcorner}$is true under an interpretation, for a singular term $a$ and a general term $P$, if and only if the value of $a$ is a member of the value of $P$ or the value of $P$ is a member of the value of $a$ under the interpretation in question.

(Correspondingly for polyadic predications.) With these elements in place, it is easy to check that, in the case described, the same sentences are again rendered true under $I^{*}$ as they were in the original interpretation.

Note that, since we are assuming that the predicative character of ways of being is aptly codified by an assignment of a set to it, in discussing the possibility that under an admissible interpretation a singular term may turn out predicative, in the sense of expressing a way for objects to be, we need to make room for the added disjunct (italicised above) in order to preserve the truth-definition for the language in question. Notice that, importantly, the same axiom might be used without loss in the derivations in the original setting. ${ }^{13}$

However, some might take issue with this addition based on the following consideration. The copula 'is' is intuitively asymmetric. Since the suggested axiom interprets it, in effect, as if it would allow for converse cases, this move is therefore unwarranted. In response, let me draw attention to the fact that it is not altogether clear that the copula 'is' is indeed asymmetric in the relevant sense (Macbride 2005: 596-599; Brown 2017). To substantiate this point, one might distinguish between two senses of asymmetry. Accordingly, a binary expression $\mathrm{R}$ is genuinely asymmetric if and only if, for appropriate expressions $\mathrm{A}$ and $\mathrm{B},{ }^{14}$ if ${ }^{\ulcorner} \mathrm{ARB}{ }^{\urcorner}$is true, then $\left\ulcorner\sim \mathrm{BRA}^{\urcorner}\right.$is true; $\mathrm{R}$ is spuriously asymmetric if and only if, for appropriate expressions $\mathrm{A}$ and $\mathrm{B}$, if ${ }^{\ulcorner} \mathrm{ARB}{ }^{\urcorner}$is true, then ${ }^{\ulcorner} \mathrm{BRA}^{\urcorner}$is nonsensical (therefore, ${ }^{\ulcorner} \sim \mathrm{BRA}^{\urcorner}$is nonsensical as well). In English, the copula is plausibly asymmetric in this latter sense, that is, e.g. 'wise is Socrates', in the reading intended, is not a well-formed expression. (Even if one allows for negation to be applied truly to such 'sentences', some distinction should still be recognised between these cases and 'genuine' negative truths, such as ' $\sim$ a is larger than b', which under plausible assumptions follows

\footnotetext{
${ }_{13}$ It is important to emphasize that, in order to establish the claim that the object-ways of being distinction is indeterminate in the relevant sense, it would strictly speaking suffice to provide an interpretation under which every general term is assigned an object, and every singular term in turn is assigned a way of being. In this, no addition to the axiom for truth of atomic predicational sentences we started with is required, but only an 'inversion' of the membership relation. However, it is plain that relying solely on this trivial transformation would hardly establish the point aimed at. The result with the alteration is more general in the sense that it allows for partial differences in the interpretation of singular and general terms in the same language.

14 That is, A and B must be such that at least one of $\left.{ }^{\ulcorner} \mathrm{ARB}\right\urcorner$ and ${ }^{\ulcorner} \mathrm{BRA}{ }^{\urcorner}$is a well-formed sentence. Though these definitions call for further clarifications, which I leave aside, for present purposes the main idea will do.
} 
from ' $b$ is larger than a', and thus provides grounds for holding that the relational predicate 'is larger than' is genuinely asymmetric in the aforementioned sense.) Not only one might thus rule out expressions of the form ${ }^{\ulcorner} P$ is $a^{\urcorner}$from being interpreted, but, more importantly, spurious asymmetry is insufficient to put a ban on the interpretation laid down above: by itself, the nonsense of the converse predication might turn on contingent linguistic matters, and is a poor sign of the non-obtaining of the corresponding 'fact' (cf. Schnieder 2006b). Though the issue would certainly call for a more detailed treatment, I take it that the reply falls short of establishing the illegitimacy of the base axiom above.

The example above rests crucially on the assumption that the language is not able to express identity. Otherwise, for example the sentence 'Garfield=Felix' would be true under the interpretation $I^{*}$, while it is false under $I$ above. To deal with cases in which identity is present, a natural idea, which I will adopt in the general formulation below, is to model the singular terms which in the original interpretation designated distinct objects as distinct ways of being, that is, sets. Thus we might for instance construe the new interpretation as assigning again to 'cat' the object Garfield; while 'Felix' gets assigned \{Garfield $\}$ and 'Garfield' e.g. $\{\{$ Garfield $\}$, Garfield $\}$.

As in the foregoing section, we proceed to the general formulation of the relation between the interpretations involved. Since, to work in every case, the relation is not characterised simply via a permutation of the domain of the original interpretation, I will state the transformation as consisting of four instructions, or steps, for the sake of simplicity and readability. I will assume that the first-order language L, characterised as above, has a singular term for every individual in the underlying domain $\mathrm{D}$, and that general terms are all monadic. ${ }^{15}$ Starting with an interpretation I of L and a domain D, we now obtain a shuffled interpretation $\mathrm{I}^{*}$, and a new domain $\mathrm{D}^{*}$, as follows:

Step 1 One at a time, according to a previously determined order of expressions (the alphabetical one, say) take each general-term $\mathrm{P}$ in $\mathrm{L}$, choose an individual $a$ such that $a \in \mathrm{I}(\mathrm{P})$, and let $\mathrm{I}^{*}(\mathrm{P})=a$, provided that for any general-term $\mathrm{Q}$ previous in the sequence, $I^{*}(P)=I^{*}(Q)$ if and only if $I(P)=I(Q)$. (For any general-term $P$ in the sequence, if $\mathrm{I}(\mathrm{P})=\varnothing$, then $\mathrm{I}^{*}(\mathrm{P})=\varnothing$.) Not every general-term will be accounted for in this way in every case. From the point in the sequence where the condition cannot be fulfilled, let $\mathrm{I}^{*}(\mathrm{P})=\mathrm{I}(\mathrm{P})$, for any subsequent general-term $\mathrm{P}$.

Step 2 For every general-term $\mathrm{P}$, for every singular term $\mathrm{S}$ in $\mathrm{L}$, let $\mathrm{I}^{*}(\mathrm{P}) \in \mathrm{I}^{*}(\mathrm{~S})$ if and only if $\mathrm{I}(\mathrm{S}) \in \mathrm{I}(\mathrm{P})$ (where $\mathrm{I}^{*}(\mathrm{P})$ is settled according to the previous step). (If for some $\mathrm{S}$, for every $\mathrm{P}, \sim(\mathrm{I}(\mathrm{S}) \in \mathrm{I}(\mathrm{P}))$, then $\left.\mathrm{I}(\mathrm{S})=\mathrm{I}^{*}(\mathrm{~S})\right)$.

Step 3 One at a time, according to a previously determined order of expressions (the alphabetical one, say), take each singular term $\mathrm{S}$ in L, and i) if for every singular term $S^{\prime}$ previous in the sequence, $I^{*}\left(S^{\prime}\right) \neq I^{*}(S)$ if and only if $I\left(S^{\prime}\right) \neq I(S)$, leave its value under $I^{*}$ unchanged, and proceed to the next; ii) if not, then choose an individual $a$ such that $a \in \mathrm{I}^{*}(\mathrm{~S})$ and let $\{a\} \in \mathrm{I}^{*}(\mathrm{~S})$, provided that for no $\mathrm{P}, \mathrm{I}^{*}(\mathrm{P})=\{a\}$; (If the latter cannot be done, proceed to $\{\{a\}\}$, and so forth).

\footnotetext{
15 Relational terms should be dealt with in an analogous fashion in each of the steps, by assigning a sequence of individuals satisfying their original interpretation whenever the procedure for monadic general terms would assign an individual to it.
} 
Remark This step is meant to ensure that identities true under the original interpretation are preserved in the new one.

Step 4 Let $D^{*}$, the domain of the new model, be $\{\mathrm{x}$ : $\exists \mathrm{S}$ ( $\mathrm{S}$ is a singular term of $\mathrm{L}$ $\left.\left.\wedge \mathrm{x}=\mathrm{I}^{*}(\mathrm{~S})\right)\right\}$, that is, the set having the values of all singular terms under the new interpretation as members.

Remark This step is needed for quantifications to work properly, since singular terms are interpreted differently under the new interpretation. Crucially, notice that the new domain is construed solely based on simple set theoretical operations on the original, that is, both interpretations concern the same 'universe of discourse' in an extended sense of this phrasing, comprising the original domain and sets built out of its members.

Let us provide an illustration of the procedure, which will help reveal the rationale behind its steps and its simplicity in practice. Consider a domain of individuals $\mathrm{D}=\{$ Obama, Plato $\}$. The language in question is taken to contain the singular terms 'Obama', 'Plato'; the general terms 'human', 'philosopher', 'politician'; the identity sign '=', logical connectives and first-order quantifiers. Take an interpretation I such that I('Obama')= Obama, I('Plato') $=$ Plato, I('human') $=\{$ Obama, Plato $\}$, $\mathrm{I}($ 'philosopher' $)=\{$ Plato $\}$, and I('politician' $)=\{$ Obama $\}$. The identity sign and the connectives are interpreted as usual.

Now to obtain a shuffled interpretation, we go through the steps. We rely on the alphabetical order for ordering singular and general terms, and start by letting $I^{*}$ ('human') = Obama, given that Obama is one individual in the value of this general term under I, and no other general term has been considered. As to the value of 'philosopher' under the new interpretation, we let $I^{*}$ ('philosopher')=Plato, since Plato is the only individual in I('philosopher'), and the condition of the first step is fulfilled. Since Obama is the only individual which is a member of I('politician'), and it is not the case according to the original interpretation that all and only humans are politicians (Plato is not), then the initial process in step 1 cannot be carried further. Thus $I^{*}$ ('politician') $=\mathrm{I}$ ('politician' $)=\{$ Obama $\}$. Proceeding to step 2 , $I^{*}($ 'Obama' $)=\{$ Obama, $\{$ Obama $\}$, since Obama is human and a politician under I, and $I^{*}($ 'Plato' $)=\{$ Obama, Plato $\}$, since Plato is human and a philosopher according to I. In this particular case, step 3 is unnecessary, since I*('Plato') $\neq \mathrm{I}^{*}$ ('Obama') according to the previous step. Finally, $D^{*}=\{\{$ Obama, Plato $\},\{$ Obama, $\{$ Obama $\}\}\}$.

By examining each of the steps, it is easy to check that interpretations thus related render the same sentences true, that is, that every closed sentence $p$ of $\mathrm{L}, p$ is true under I (relative to D) iff $p$ is true under $I^{*}$ (relative to $\mathrm{D}^{*}$ ), so that a result analogous to the one of the previous section holds. Significantly, under $I^{*}$ some singular terms get ways of being - that is, sets-, while some general terms get objects as semantic values.

Two observations concerning the construction thus outlined are worth stressing. Firstly, note that it is a supposition of the argument that at least one of the general term or singular term in each predicative sentence gets assigned a set. This mirrors 
the assumption that there is a distinction between objects and ways of being in good standing.

Secondly, as already mentioned, the relation between the original interpretation and the deviating interpretation is not determined by a permutation of the original domain. But this is far from objectionable: while it would be surely awkward to label it a 'permutation argument', that the original argument makes use of a bijective function to coin the equivalent interpretation is not essential to its point. As remarked earlier, it suffices to establish P2 that one alternative interpretation of the language in question be provided which renders the same sentences true, while interpreting sub-sentential terms differently. Plainly, one does not need a permutation to show this in every case. Admittedly, when formulated in generality, the construction might strike one as artificial, at any rate more artificial than permutations, on which Putnam's point rests. However, this artificiality is arguably forced upon us by the very issue we are dealing with, which is severely constrained by limitations of natural language, and it is not clear that one might advance any argument on this without engaging in similarly contrived considerations. Notwithstanding its artificiality, it is still a perfectly feasible procedure, which relies solely on set-theoretic apparatus, as in Putnam's original case.

In conclusion of this section, let us get clearer on how this argument relates to Putnam's, and how it is supposed to have a bearing on P2 and the indeterminacy of the distinction between objects and ways of being more generally. To recall, it was stated above that a distinction between P's and Q's is indeterminate whenever we cannot settle on satisfactory grounds, concerning at least some cases, whether they are to be classified as P's or Q's. In particular, the main argument targets the conclusion that objects and ways of being satisfy this scheme.

To prevent misunderstanding, it should be first noted that Putnam's original argument need not be read as establishing an indeterminacy claim of any distinction along these lines. Though one could perhaps insist that it does suggest the indeterminacy of the distinction between intended and non-intended interpretations, or relations of reference, or maybe even between expressions which refer to a certain object and those which do not, it certainly is not meant to show, for instance, that a distinction between objects themselves, e.g. Socrates and Aristotle, is indeterminate in any sense. ${ }^{16}$

Relatedly, though obviously inspired by Putnam, the argument of the present section does not depend on, let alone entails, the success of the permutation argument. ${ }^{17}$ In fact, notice that some replies to Putnam's contention might prove ineffective concerning the present case. Take, for instance, the influential suggestion that

\footnotetext{
16 Note that it is usual to report the result of permutation arguments as establishing some kind of indeterminacy (see e.g. Quine 1960 on 'indeterminacy of translation'). The clarification in the main text points out only that there might be different senses of the term in play.

17 This is important, for one could think that, by the adopted strategy, one is committed to the claim that, whenever there are equivalent interpretations of expressions $\mathrm{E}$ and $\mathrm{E}$, then a distinction between their values is indeterminate in our sense, which at least flirts with absurdity if applied to the permutation argument itself. For what's worth, a modification of the mentioned claim by restricting E and E' to distinct grammatical categories (sentences, singular terms, general terms, connectives, and so on) does strike me with an air of plausibility. However, as the comments should make clear, I need not commit myself to any general principle of this sort, but solely insist that this holds in the particular case in which
} 
some reference relations are less gerrymandered, or more natural, than others, in the sense that some objects are 'more eligible' for reference than others (Merrill 1980; Lewis 1984). Worries with the cogency of the notion of naturalness aside, this reply seems to at most narrow down which permutations are permissible in the argument (as explicitly acknowledged by Lewis). However, it is unclear that the same could be said by way of settling a choice between interpretations differing with respect to a certain sentence solely as to whether an object or a way of being is assigned to either of the expressions therein. To put it in more tractable terms, it does not seem that the same considerations pertaining to naturalness are effective in selecting the assignment of Socrates or Socratises to 'Socrates', or analogously of wise or (this) wisdom to 'wise'. Without going into detail about Merrill's and Lewis's replies, let me just note that, at the very least, these considerations seem to require strengthening in order to be effective in these cases. For one, they focus only on a comparison of eligibility between elements in one 'category', that is between either objects or ways of being, and it is unclear that one might flesh out a notion of naturalness which would enable us to compare objects, on the one hand, and ways of being, on the other. (Even reliance on a notion of naturalness applying to linguistic expressions does not obviously take us farther in this regard.) Besides, even if we concentrate solely on ways of being, we might be at a loss when applying naturalness to the relevant cases. For instance, that wise makes for more similarity between what is wise than Socratises does does not seem promising, since not only do instances of Socratises, as a rule, even occupy the same spatio-temporal region, but there might be cases this type of consideration does not seem to settle ('This electron is negatively charged', for instance). Though the issue certainly calls for a more thorough comment, these remarks suffice to show that the present argument brings new elements into play.

Finally, and most importantly, it might be put to doubt that a permutation argument, or anything along the lines of the present construction, even if successful, can establish indeterminacy in the sense aimed at, since merely showing that there are intuitively 'conflicting' interpretations assigning the same truth-values to the corresponding sentences might seem insufficient for the point at stake.

This worry is similar to one raised against Putnam's original argument, and invites two qualifications by way of response. Firstly, both Putnam's and the present argument do not show merely that if there is an interpretation of a language, then there is an equivalent, deviant interpretation, in our case switching some of the values for general terms by those of singular terms, but demonstrably, based on settheoretical machinery, that there must be (Taylor 2006: 56). ${ }^{18}$

Footnote 17 (continued)

E is a singular, and E' a general term. Thanks to an anonymous referee for interesting discussion on this point.

18 With the exception of interpretations assigning only empty extensions to general terms, in which case the present construction cannot deliver a deviant, shuffled interpretation. Since, however, these are exceptional in themselves, they do not seem to threaten the argument substantively. 
Secondly, as highlighted previously, the argument does establish that if our distinction between objects and ways of being should draw its credentials solely from what the truth-conditions of whole sentences require, then the distinction is indeterminate in the relevant sense (see the discussion on P1 above). And this result, if only due to the analogy with Putnam's argument, is of interest in its own right. To be sure, as already mentioned, it might be that this antecedent turns out false, since the distinction might turn on considerations of a wholly different nature, or maybe the notion of what a truth-condition requires might be modified so as to avoid the argument (cf. Wallace 1977: 155-156; Hale and Wright 1997: 434). Since addressing all the alternative replies would go beyond the scope of this paper, we must at present rest content with the result in this conditional form. ${ }^{19}$

\section{Drawing some morals}

Time to take stock. I have presented an argument against the determinacy of the distinction between objects and ways of being, the bulk of which is the second premise. The argument for the latter resembles Putnam's original permutation argument, while differing from it in important respects. In a nutshell, the argument is designed to show that we are not entitled to read off from the functions of subject and predicate in a sentence what is to count as an object and a way of being 'out there'. To put the point in other terms, I have spoken of an indeterminacy concerning what are objects and what are ways for these objects to be. In this section, I will suppose the argument is sound, and state two morals one might draw from this.

First, the claim that the object-way of being distinction is indeterminate has as a consequence that what first- and second-order variables range over is not settled offhand. This has an obvious bearing to common strategies trying to mitigate firstorder ontological commitment to entities by pointing to equivalent formulations which do not incur in such commitments, that is strategies which 'trade ontology for ideology', to use Quine's terms. This is not to say that the availability of such formulations is without importance, but only to point out that, since in light of the indeterminacy they underwrite predications which might equally correspond to the same objects as the original, in themselves the translations are far from settling the issue over whether the initial theory is free from the commitments this move is meant to make it escape from.

\footnotetext{
19 It is not clear that the result generalises to every distinction between values of subsentential expressions belonging to distinct categories, as for instance operators, predicate modifiers, and so on. Even if it does, since it is to be expected that the intuitive case for the determinacy of the corresponding distinctions is weaker than in the present case, I fail to see that this would be objectionable. Given the ubiquity of predications, certainly the distinction between objects and ways of being stands out as one of distinctive interest. Thanks to an anonymous referee for bringing me to say something on this.
} 
Second, and relatedly, the result might help alleviate uneasy feelings towards some particular philosophical position. To mention one specifically interesting case, consider necessitism, the view that necessarily, everything is necessarily something (with both quantifiers read first-order). Even its most prominent defender is ready to admit the initial oddness of this claim (Williamson 2013: 1). In particular, it seems at first odd to accept that this paper, this table and other objects could not have failed to exist. But if the indeterminacy holds, we are not entitled to suppose that these are values of the variables occurring in the claim expressing the view. If one does not feel the same oddity concerning the usual values of second-order variables, that is, if one does not have qualms with the necessary existence of what we usually take as ways for things to be, the door is open to an interpretation in which necessitism loses then much of its intuitive awkwardness. In other words, the sole possibility, supported by the argument above, that objects be other things than what we usually take them to be might make the view less objectionable. ${ }^{20}$

\section{Conclusion}

One of the honourable tasks of metaphysics consists in drawing a line between features of our representations of reality and how reality is in itself. While in some cases the difference is less controversially attributed to the representational part-for instance, the difference between sentences in active and passive voice, or sentences differing only by strictly synonymous terms - some cases might be only decided upon the scrutiny of arguments.

The permutation argument shows that one and the same language might be interpreted in a variety of ways which preserve the intuitively correct truth-conditions of its sentences, while diverging significantly on the interpretation of the singular and general terms occurring in the latter. This Putnam took to show that what subsentential terms refer to is not a fixed matter, as a realist position would have it be.

In this paper, I presented a straightforward extension of the permutation argument which shows that the truth-conditions of sentences is also unable to pick out a unique assignment of expressions functioning as subject and predicate to either objects or ways of being. In parallel with Putnam's reading of the original result, I took this to show that, though one might draw the distinction between objects and ways in general on the basis of the subject-predicate structure of predicative sentences, as far as the truth of these sentences go, a choice between which of the terms in the sentence corresponds to the object(s), and which to the way this object purportedly is, remains unsettled, that is, that reality is indifferent to whether something is parsed as an object or as a way for an object to be.

\footnotetext{
${ }^{20}$ This point presupposes that one might endorse first-order necessitism while rejecting its higher-order variant. For discussion of the derivation of Barcan formulas in second order modal logics, see Williamson (2015).
} 
Acknowledgements I thank two anonymous referees of this journal for comments on a previous version of this paper and helpful discussion.

Funding Open Access funding enabled and organized by Projekt DEAL.

Open Access This article is licensed under a Creative Commons Attribution 4.0 International License, which permits use, sharing, adaptation, distribution and reproduction in any medium or format, as long as you give appropriate credit to the original author(s) and the source, provide a link to the Creative Commons licence, and indicate if changes were made. The images or other third party material in this article are included in the article's Creative Commons licence, unless indicated otherwise in a credit line to the material. If material is not included in the article's Creative Commons licence and your intended use is not permitted by statutory regulation or exceeds the permitted use, you will need to obtain permission directly from the copyright holder. To view a copy of this licence, visit http://creativecommons.org/licen ses/by/4.0/.

\section{References}

Brown, S. (2017). Against instantiation as identity. Philosophical Studies, 174, 887-900.

Button, T. (2013). The limits of realism. Oxford: Oxford University Press.

Correia, F. (2016). On the logic of factual equivalence. The Review of Symbolic Logic, 9(1), 103-122.

Douven, I. (1999). Putnam's model-theoretic argument reconstructed. Journal of Philosophy, 96(9), 479-490.

Dummett, M. (2015). What do permutation arguments prove. In R. Auxier, et al. (Eds.), The philosophy of Hillary Putnam. The library of living philosophers (Vol. XXXIV) (pp. 419-436). Chicago: Open Court.

Frege, G. (1893/2013). The fundamental laws of arithmetic. Oxford: Oxford University Press. English translation by Ebert, Philip A. and Rossberg, Marcus.

Hale, B., \& Wright, C. (1997). Putnam's model-theoretic argument against metaphysical realism. In B. Hale \& C. Wright (Eds.), A companion to the philosophy of language (pp. 427-457). Oxford: Blackwell.

Krämer, S. (2014). On what there is for things to be. Studies in Theoretical Philosophy (Vol. 1). Frankfurt: Vittorio Klostermann Verlag.

Künne, W. (2006). Properties in abundance. In P. F. Strawson \& A. Chakrabarti (Eds.), Concepts, properties and qualities (pp. 249-300). Farnham: Ashgate.

Levinson, J. (1978). Properties and related entities. Philosophy and Phenomenological Research, $39(1), 1-22$.

Lewis, D. (1984). Putnam's paradox. The Australasian Journal of Philosophy, 62, 221-236.

MacBride, F. (2005). The particular-universal distinction: A dogma of metaphysics? Mind, 114(455), 565-614.

MacBride, F. (2006). Predicate reference. In B. C. Smith (Ed.), The Oxford handbook of philosophy of language (pp. 422-475). Oxford: Oxford University Press.

Merrill, G. H. (1980). The model-theoretic argument against realism. Philosophy of Science, 47(1), 69-81.

Mulligan, K., Simons, P., \& Smith, B. (1984). Truth-makers. Philosophy and Phenomenological Research, 44(3), 287-321.

Prior, A. (1971). Objects of thought. Oxford: Clarendon Press.

Putnam, H. (1980). Models and reality. Journal of Symbolic Logic, 45(3), 464-482.

Putnam, H. (1981). Reason, Truth and History. Cambridge: Cambridge University Press.

Quine, W. (1960). Word and object. Cambridge: MIT Press.

Ramsey, F. P. (1925). Universals. Mind, 34(136), 401-417.

Rayo, A., \& Yablo, S. (2001). Nominalism through de-nominalization. Noûs, 35(1), 74-92.

Schnieder, B. (2006a). Attributing properties. American Philosophical Quarterly, 43(4), 315-328.

Schnieder, B. (2006b). 'By Leibniz's law': Remarks on a fallacy. The Philosophical Quarterly, 56, 39-54. 
Schwartzkopff, R. (2016). Singular terms revisited. Synthese, 193(3), 909-936.

Sellars, W. (1960). Grammar and existence: A preface to ontology. Mind, 69(276), 499-533.

Strawson, P. F. (1971). The asymmetry of subjects and predicates. In P. F. Strawson (Ed.), LogicoLinguistic papers (pp. 96-115). London: Methuen \& Co.

Strawson, P. F. (1974). Subject and predicate in logic and grammar. London: Methuen \& Co.

Taylor, B. (2006). Models, truth, and realism. Oxford: Oxford University Press.

Wallace, J. (1977). Only in the context of a sentence do words have any meaning. Midwest Studies in Philosophy, 2(1), 144-164.

Williamson, T. (2013). Modal logic as metaphysics. Oxford: Oxford University Press.

Williamson, T. (2015). Barcan formulas in second-order modal logic. In M. Frauchiger (Ed.), Themes from Barcan Marcus (pp. 51-74). Berlin: Ontos Verlag.

Publisher's Note Springer Nature remains neutral with regard to jurisdictional claims in published maps and institutional affiliations. 